\title{
Ксенотим-(Y) из мусковитовых пегматитов юго-восточной оконечности п-ова Канин
}

\author{
Соболева А.А., Филиппов В.Н.
}

Институт геологии ФИЦ Коми НЦ УрО РАН, Cыктывкар, aa_soboleva@mail.ru

\begin{abstract}
Аннотация. Исследован ксенотим-(Y) из мусковитовых пегматитов юго-восточной оконечности п-ова Канин, локализованных среди докембрийских пород микулкинской серии, метаморфизованных в условиях амфиболитовой фации. Ксенотим-(Y) встречается в виде кристаллов размером 50-400 мкм и синтаксических сростков с цирконом. Выявлено неоднородное пятнистое внутреннее строение зерен ксенотима. Наличие чередующихся светлых и темных в режиме BSE участков, в разной степени обогащенных U, постоянство их состава, отсутствие корреляции содержаний U и Th с другими элементами, входящими в состав ксенотима, позволяет предположить, что пятнистое строение ксенотима-(Y) обусловлено распадом высокотемпературного ксенотимового твердого раствора при остывании пегматитового тела.
\end{abstract}

Ключевые слова: ксенотим-(Y), пегматиты, циркон, п-ов Канин.

\section{Xenotime-(Y) from muscovite pegmatite of the southeastern extremity of the Kanin Peninsula}

\author{
Soboleva A.A., Filippov V.N. \\ Institute of Geology, FRC Komi Scientific Center, UB RAS, Syktyvkar,aa_soboleva@mail.ru
}

\begin{abstract}
Xenotime-(Y) from muscovite pegmatite located in the southeastern extremity of the Kanin Peninsula within Precambrian rocks of the Mikulkinskaya Group metamorphosed under amphibolite facies conditions was studied. Xenotime-(Y) occurs as crystals $50-400 \mu \mathrm{m}$ in size and syntactic intergrowths with zircon. We revealed patchy zoning internal texture of xenotime grains. The presence of alternating light and dark in BSE clusters enriched in $U$ in varying degrees, the constancy of their composition, and the lack of correlation of the $U$ and Th contents with other elements that constitute xenotime suggests that patchy zoning texture of xenotime-(Y) resulted from decomposition of high-temperature xenotime solid solution during cooling of the pegmatite body.
\end{abstract}

Key words: xenotime- (Y), pegmatite, zircon, Kanin Peninsula.

\section{Введение}

Полуостров Канин представляет собой приподнятый блок Тиманской гряды, где верхнедокембрийские осадочно-метаморфические толщи и магматические породы позднерифейскогокембрийского возраста слагают хребет Канин Камень. В осевой части этого хребта обнажаются преимущественно терригенные породы, которые во многих местах прорваны долеритами, а также на одном участке побережья Баренцева моря на северо-западе п-ова Канин - мусковит-биотитовыми гранитами с U-Pb возрастом $883 \pm 16$ млн. лет, монцонитоидами и лампрофирами с U-Pb возрастами $505 \pm 7$ млн. лет и $504 \pm 7$ млн. лет соответственно (Андреичев и др., 2018). Пегматитовые жилы выходят на поверхность на крайнем юго-востоке полуострова в поле распространения пород микулкинской серии. Граниты, с которыми могли бы быть связаны пегматиты, не выходят на поверхность и не вскрыты скважинами, их наличие предполагается только по геофизическим данным (Гецен и др., 1985). Возраст пегматитов, определенный K-Ar методом по монофракциям мусковита и полевых шпатов - 640-494 млн. лет (Мальков, Пучков, 1964, Костюхин, 1984).

\section{Геологическая позиция пегматитов}

Наиболее ранние опубликованные сведения о гранитных пегматитах п-ова Канин принадлежат Ю.П. Ивенсену, который описал морфологию пегматитовых жил и особенности их минерального состава (Ивенсен, 1964). Геолого-структурная позиция, формационная принадлежность, петрогенезис этих пород и результаты изучения породообразующих минералов нашли позднее отражение в работах В.Г. Гецена и М.Н. Костюхина (Гецен, 1975, Костюхин, 1979, Костюхин, 1984, Костюхин, Степаненко, 1987). 

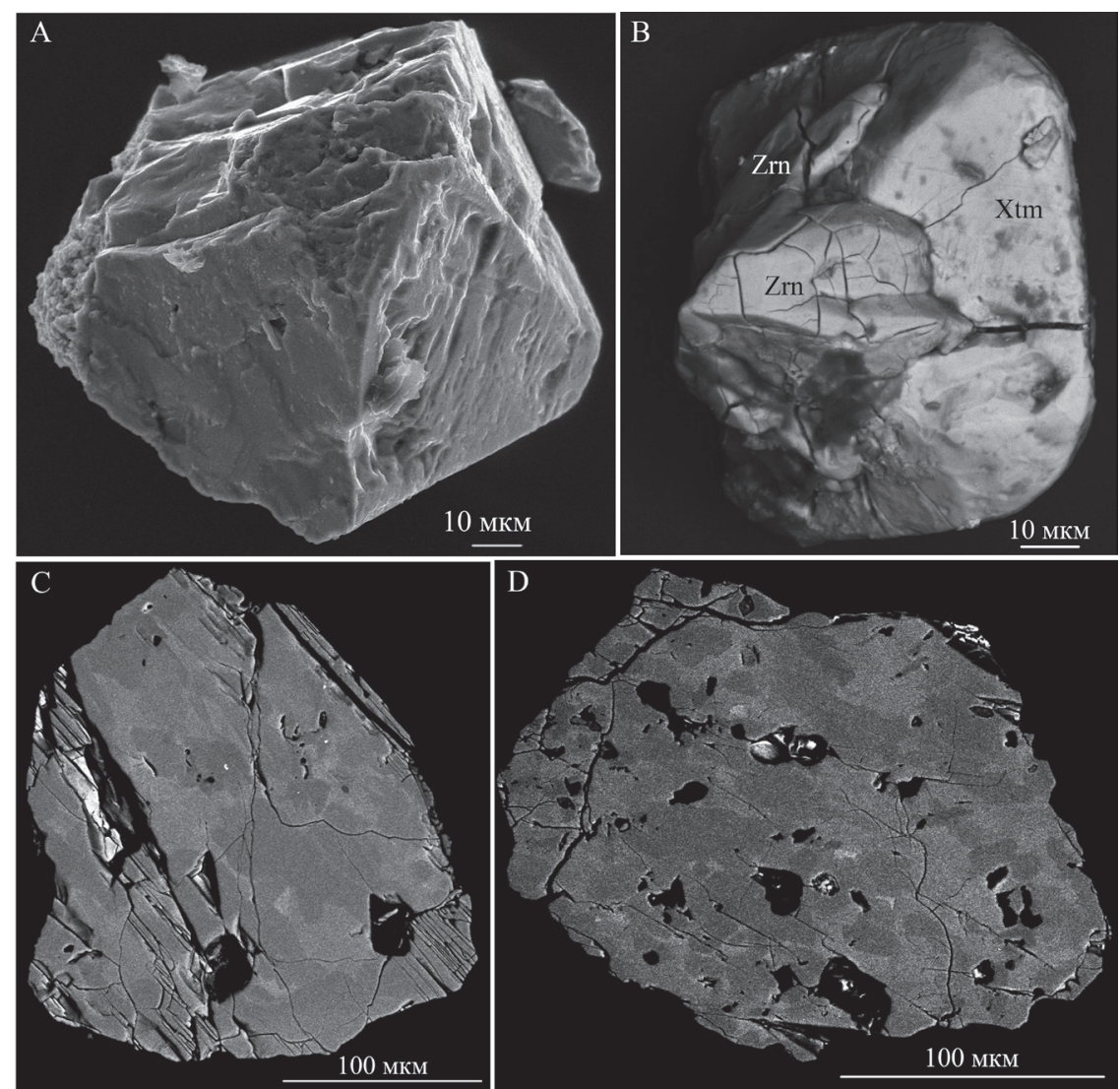

Рис. 1. Ксенотим-(Y) из мусковитовых пегматитов юго-восточной части п-ова Канин.

A - кристалл ксенотима-(Y), В - синтаксический сросток ксенотима-(Y) и циркона, С и D - внутреннее пятнистое строение зерен ксенотима-(Y). Изображения в режимах вторичных (А) и упруго-отраженных (B-D) электронов и состав минералов получены на микрозонде JEOL (JSM-6400) с энергодисперсионным спектрометром LINK в ЦКП «Геонаука» УрO РАН в г. Сыктывкар.

Fig. 1. Xenotime-(Y) from muscovite pegmatites of the southeastern part of the Kanin Peninsula. A - crystal of xenotime-(Y), B - syntactic intergrowth of xenotime-(Y) and zircon, C and D - internal patchy zoning texture of xenotime-(Y) grains. SE (A) and BSE (B-D) images, and compositions of minerals were obtained with JEOL microprobe (JSM-6400) equipped with LINK energy dispersive spectrometer at the «Geonauka» Center for Collective Use of the Ural Branch of the Russian Academy of Sciences in Syktyvkar.

Жилы гранитных пегматитов сконцентрированы на южном и восточном побережье Чёшской губы в районе мыса Микулкин. Вмещающие породы микулкинской серии представлены гранаткварц-биотитовыми кристаллическими сланцами, содержащими участками дистен и ставролит (Костюхин, Степаненко, 1987). Сланцы чередуются с прослоями гранат-биотитовых кварцитов. Пегматитовые тела располагаются в зоне развития дистен-альмандиновой субфации регионального метаморфизма дистен-силлиманитового типа (Новицкий, 1976).

Выделяется три типа пегматитовых жил - послойные жилы, расположенные согласно сланцеватости вмещающих метаморфических пород микулкинской серии (1); жилы, секущие сланцеватость, но смятые в складки вместе с кристаллосланцами (2) и наиболее поздние прямолинейные секущие жилы (3), постметаморфические и постскладчатые (Костюхин, Степаненко, 1987).

М.Н. Костюхиным пегматиты Канина были отнесены к мусковитовой формации и к группе пегматитов больших глубин (Костюхиин, Степаненко, 1987). Температура начальных стадий образования пегматитов Канин оценивается как $600-680^{\circ} \mathrm{C}$ при общем давлении 6-8 кбар и давлении воды 3-3.5 кбар (Новицкий, 1975). Завершение процесса пегматитообразования происходило при $400-510^{\circ} \mathrm{C}$ (Костюхин, 1979). 
Таблица 1. Средний состав светлых и темных (в режиме BSE) участков ксенотима, мас. \%. Table 1. Average composition of bright and dark (in BSE) xenotime clasters, wt. \%.

\begin{tabular}{|c|c|c|c|c|c|c|}
\hline \multirow{2}{*}{ Компоненты } & \multicolumn{3}{|c|}{ Светлые участки $(\mathrm{N}=57)$} & \multicolumn{3}{c|}{ Темные участки $(\mathrm{N}=58)$} \\
\cline { 2 - 7 } & Пределы & Среднее & СКО & Пределы & Среднее & СКО \\
\hline $\mathrm{P}_{2} \mathrm{O}_{5}$ & $27.64-33.05$ & 30.79 & 1.09 & $28.38-34.14$ & 31.12 & 1.40 \\
\hline $\mathrm{Y}_{2} \mathrm{O}_{3}$ & $43.80-49.94$ & 47.00 & 1.22 & $44.67-52.19$ & 48.41 & 1.72 \\
\hline $\mathrm{Sm}_{2} \mathrm{O}_{3}$ & $0.48-1.96$ & 1.13 & 0.26 & $0.44-1.78$ & 1.08 & 0.34 \\
\hline $\mathrm{Gd}_{2} \mathrm{O}_{3}$ & $2.55-5.79$ & 4.74 & 0.59 & $3.64-5.70$ & 4.80 & 0.55 \\
\hline $\mathrm{Tb}_{2} \mathrm{O}_{3}$ & $0-2.64$ & 1.24 & 0.69 & $0.26-2.89$ & 1.21 & 0.62 \\
\hline $\mathrm{Dy}_{2} \mathrm{O}_{3}$ & $5.60-8.28$ & 6.76 & 0.54 & $5.47-9.30$ & 6.99 & 0.83 \\
\hline $\mathrm{Ho}_{2} \mathrm{O}_{3}$ & $0.08-2.98$ & 1.21 & 0.67 & $0.51-2.37$ & 1.36 & 0.51 \\
\hline $\mathrm{Er}_{2} \mathrm{O}_{3}$ & $1.61-4.59$ & 3.05 & 0.58 & $1.52-4.55$ & 3.08 & 0.63 \\
\hline $\mathrm{Tm}_{2} \mathrm{O}_{3}$ & $0.01-1.07$ & 0.60 & 0.18 & $0.12-1.33$ & 0.56 & 0.45 \\
\hline $\mathrm{Yb}_{2} \mathrm{O}_{3}$ & $0.96-3.56$ & 2.10 & 0.54 & $1.10-4.17$ & 2.14 & 0.67 \\
\hline $\mathrm{ThO}_{2}$ & $0-1.26$ & 0.50 & 0.31 & $0.01-1.03$ & 0.40 & 0.11 \\
\hline $\mathrm{UO}_{3}$ & $0.69-4.00$ & 2.61 & 0.59 & $0-3.05$ & 0.89 & 0.25 \\
\hline
\end{tabular}

Нами были исследован ксенотим, отобранный из пробы, взятой из центральной части наиболее крупного секущего доскладчатого тела пегматитов (67.82026 ${ }^{\circ}$.ш., $46.70011^{\circ}$ в.д.), имеющего видимую мощность 38 м. Тело имеет отчетливо зональное строение. Внешняя его зона видимой мощностью 3-5 м сложена крупнозернистыми пегматитами с графической структурой. Внутренняя зона мощностью 30 м представлена блоковыми гранат-мусковит-кварц-полевошпатовыми пегматитами, содержащими кристаллы калиевого полевого шпата размером до 15 см и дымчатого кварца - до 10 см, мусковита размером первые сантиметры и зерна граната (спессартина-альмандина) размером до 8 мм, распределенные неравномерно, участками. В пегматитовых жилах этого типа установлены, кроме перечисленных минералов, биотит, апатит, циркон, ильменит, дистен, монацит, анатаз, пирит, халькопирит и халькозин (Костюхин, Степаненко, 1987).

\section{Результаты изучения ксенотима}

Ксенотим-(Y) был выделен из тяжелой электромагнитной фракции пробы мусковитового пегматита. Он представлен самостоятельными зернами и их обломками размером 50-400 мкм (рис. 1, А), в которых часто можно видеть грани тетрагональной бипирамиды $\{011\}$ и иногда пинакоида $\{001\}$. Зерна желтовато-коричневого цвета, непрозрачные, в режиме вторичных электронов выглядят крепкими и однородными. На гранях кристаллов в электронном микроскопе часто наблюдается параллельная штриховка, а в зернах видны параллельные плоскости спайности. Ксенотим-(Y), кроме того, встречается в виде ориентированных синтаксических сростков с цирконом (рис. 1, В). Подобные срастания отмечаются в пегматитах из разных регионов мира, например, в работах (Лабунцов, 1939, Попов и др,, 2006, Попова и др., 2016, Wan Fuad Wan Hassan, 1989 и др.).

Полированные срезы изученных нами кристаллов ксенотима-(Y) демонстрируют их весьма неоднородное, но во всех случаях однотипное внутреннее строение. На изображениях в режиме упруго-отраженных электронов (рис. 1, C, D) видно, что зерна состоят из чередующихся более светлых и более темных участков. Нельзя сказать, что осветление наблюдается по периферии зерен или по трещинам и вокруг полостей. Эти участки неправильной формы с достаточно четкими границами имеют размеры примерно от 10 до 100 мкм.

Среди редкоземельных элементов, замещающих иттрий в исследованном ксенотиме-(Y), преобладают Dy $\left(\mathrm{Dy}_{2} \mathrm{O}_{3}-5.47-9.30\right.$ мас. \%), $\mathrm{Gd}\left(\mathrm{Gd}_{2} \mathrm{O}_{3}-2.55-5.79\right.$ мас. \%), $\operatorname{Er}\left(\mathrm{Er}_{2} \mathrm{O}_{3}-1.52-4.59\right.$ мас. \%). 


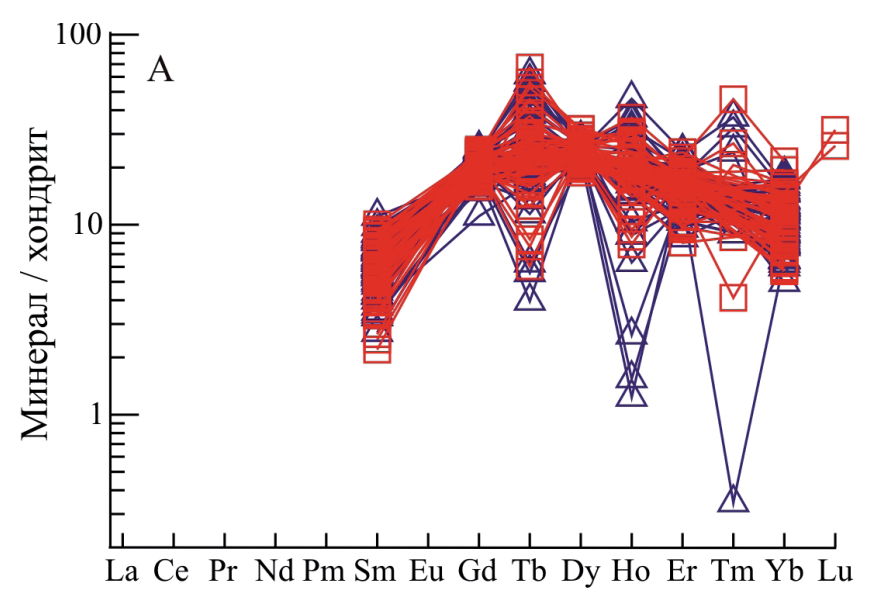

B
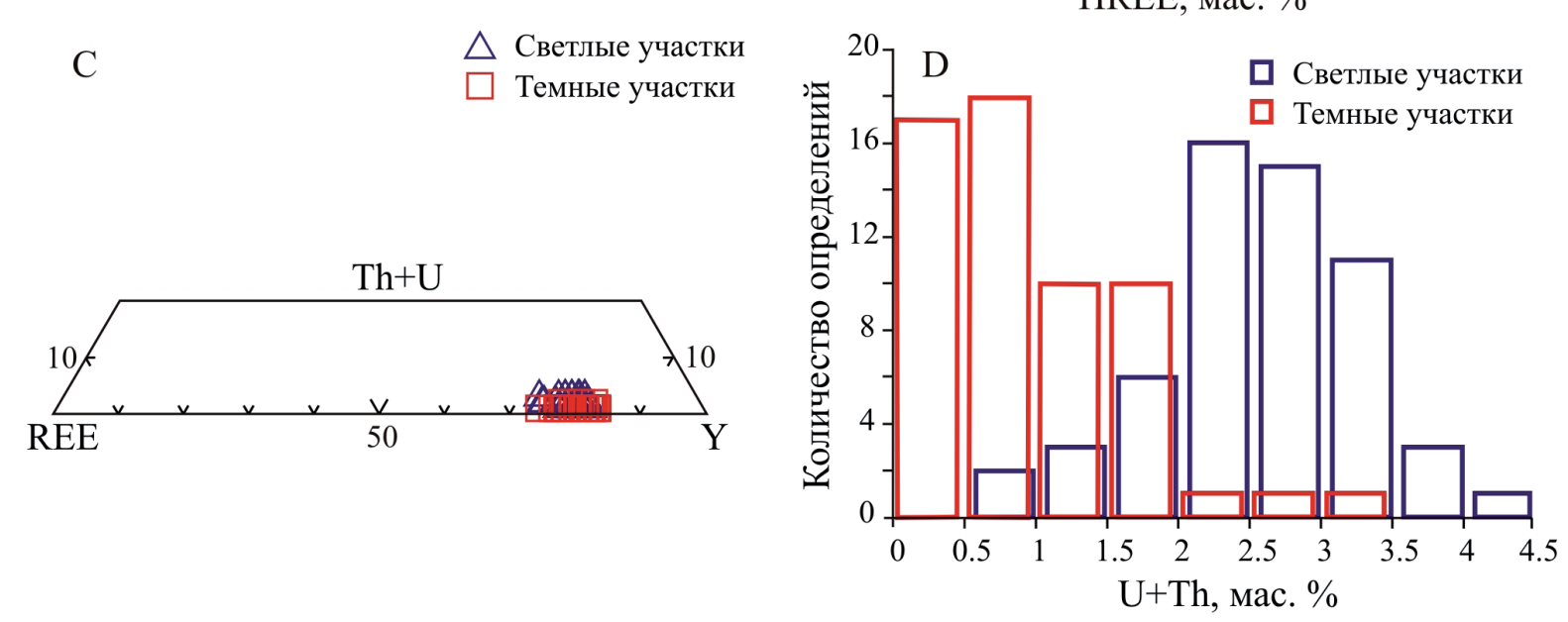

Рис. 2. Состав светлых и темных (в режиме BSE) участков зерен ксенотима-(Y) на графике распределения REE, нормированных к хондриту CI (A), диаграммах MREE-HREE (B) и REE-(Th+U)-Y (C), гистограмме распределения U+Th (D). REE - сумма редких земель, MREE - средние редкие земли (Sm-Dy), HREE - тяжелые редкие земли (Но-Lu). Состав хондрита CI по (Sun, McDonough, 1989).

Fig. 2. Composition of bright and dark (in BSE) clusters of xenotime-(Y) grains on CI chondrite-normalized REE patterns (A), MREE-HREE (B) and REE-(Th+U)-Y (C) diagrams, U+Th histogram (D). REE - sum of rare earth elements, MREE - medium rare earth elements (Sm-Dy), HREE - heavy rare earth elements (Ho-Lu). Chondrite CI composition after (Sun, McDonough, 1989).

Постоянно присутствуют $\mathrm{Yb}\left(\mathrm{Yb}_{2} \mathrm{O}_{3}-0.96-4.17\right.$ мас. \%) и $\mathrm{Sm}\left(\mathrm{Sm}_{2} \mathrm{O}_{3}-0.44-1.96\right.$ мас. \%), часто определяются $\mathrm{Tb}\left(\mathrm{Tb}_{2} \mathrm{O}_{3}\right.$ до 2.89 мас.\%) и $\mathrm{Ho}_{2}\left(\mathrm{Ho}_{2} \mathrm{O}_{3}\right.$ до 2.98 мас. \%) и иногда - $\mathrm{Tm}\left(\mathrm{Tm}_{2} \mathrm{O}_{3}\right.$ до 1.33 мас. \%). $\mathrm{U}$ (до 4 мас. $\% \mathrm{UO}_{3}$ ) и $\mathrm{Th}$ (до $1.26 \% \mathrm{ThO}_{2}$ ) содержатся практически во всех зернах ксенотима-(Y).

Светлые и темные в режиме упруго-отраженных электронов участки ксенотима-(Y) очень близки по содержаниям оксидов главных элементов $-\mathrm{P}_{2} \mathrm{O}_{5}, \mathrm{Y}_{2} \mathrm{O}_{3}, \mathrm{Dy}_{2} \mathrm{O}_{3}, \mathrm{Gd}_{2} \mathrm{O}_{3}, \mathrm{Er}_{2} \mathrm{O}_{3}, \mathrm{Yb}_{2} \mathrm{O}_{3}$ и $\mathrm{Sm}_{2} \mathrm{O}_{3}$ (табл. 1). Между ними нет заметных различий по концентрациям и характеру распределения редкоземельных элементов (рис. 2, A), так же как и по соотношению средних (MREE) и тяжелых (HREE) редких земель (рис. 2, В). Единственным обнаруженным отличием является содержание U, которым заметно обогащены светлые участки, где среднее содержание $\mathrm{UO}_{3}$ составляет $2.61 \pm 0.59$ мас. \% против $0.89 \pm 0.25$ мас. \% в темных участках (табл. 1, рис. 2, С). В светлых участках также чуть выше содержание $\mathrm{ThO}_{2}$, но из-за низкой его концентрации эта тенденция прослеживается намного хуже. Гистограмма распределения суммы $\mathrm{U}$ и Th (рис. 2, D) подтверждает, что светлые и темные участки имеют вполне определенные и достаточно постоянные составы. В 54 \% случаев светлые участки ксенотима-(Y) содержат от 2 до 3 мас. \% суммы (U+Th) с максимумом встречаемости в интервале 2-2.5 мас. \%. Для темных участков в $60 \%$ анализов содержание $(\mathrm{U}+\mathrm{Th})$ менее $1 \%$, а наиболее распространены составы с 0.5-1 мас. \%. 
Между концентрациями U и Th существует незначительная положительная корреляция: величина коэффициента корреляции Пирсона составляет 0.20 в светлых участках и 0.34 - в темных. Значимой связи $\mathrm{U}$ и Th с другими элементами, входящими в состав изученного ксенотима-(Y), не обнаруживается.

\section{Обсуждение результатов}

Неоднородное пятнистое строение ксенотима-(Y) устанавливалось и ранее при изучении минералогии пегматитов. Так, например, в работе В.И. Поповой с соавторами в ксенотиме-(Ү) из гранитных пегматитов г. Сорочьей на Южном Урале отмечаются светлые в упруго-отраженных электронах участки ксенотима с содержанием 1.3-1.4 мас. \% $\mathrm{UO}_{2}$ и более темные участки с 0.5-0.9 мас. \% $\mathrm{UO}_{2}$ (Попова и др., 2016). В этой работе делается предположение о том, что расположение более урановых участков приурочено к секторам роста кристалла ксенотима. Однако наши результаты изучения многочисленных зерен ксенотима-(Y) и его синтаксических срастаний с цирконом показывают, что такие обогащенные и обедненные $\mathrm{U}$ зоны распределены в ксенотиме более-менее равномерно и обуславливают пятнистое внутреннее строение его зерен. При этом состав этих участков достаточно постоянен, примерно одинаковы и размеры. Постоянство состава таких участков и отсутствие корреляции содержаний $\mathrm{U}$ и Th с концентрациями других элементов, входящих в состав ксенотима, наводит на мысль, что неоднородное строение зерен не является результатом наложенных гидротермальных изменений, которые скорее всего приводили бы к постепенным изменениям состава ксенотима, локализации измененных участков вблизи поверхности зерен, трещин или пор, а является результатом распада высокотемпературного ксенотимового твердого раствора и произошло при остывании пегматитового тела.

\section{Литература}

1. Андреичев В.Л., Соболева А.А., Сергеев С.А., Пресняков С.Л. Цирконовая хронология интрузивного магматизма полуострова Канин // Известия вузов. Геология и разведка. 2018. № 4. С. 30-38.

2. Гецен В.Г. Строение фундамента Северного Тимана и полуострова Канин. Л. Изд-во: Наука. 1975. 144 с.

3. Гецен В.Г., Андреичев В.Л., Степаненко В.И. Эволюция метаморфизма верхнепротерозойского комплекса Тимана по геолого-геохронологическим данным // ДАН СССР. 1985. Т. 285. № 6. С. 1424-1428.

4. Ивенсен Ю.П. Магматизм Тимана и полуострова Канин. М.-Л. Изд-во: Наука. 1964. 126 с.

5. Костюхин М.Н. Петрология гранитных пегматитов юго-восточной части полуострова Канин / Труды Ин-та геологии Коми фил. АН СССР. 1979. Вып. 29. С. 39-51.

6. Костюхин М.Н. Структурно-геологические типы жил гранитных пегматитов юго-восточной части полуострова Канин / Труды Ин-та геологии Коми фил. АН СССР. 1984. Вып. 48. С. 16-26.

7. Костюхин М.Н., Степаненко В.И. Байкальский магматизм Канино-Тиманского региона. Л. Изд-во: Наука. 1987. 232 с.

8. Лабунцов А.Н. Пегматиты Северной Карелии и их минералы. М.-Л. Изд-во: АН СССР. 1939. 260 с. (Пегматиты СССР. Т. II).

9. Мальков Б.А., Пучков В.Н. Стратиграфия и структура метаморфических толщ полуострова Канин и Северного Тимана / Вопросы геологии северо-востока Русской платформы, Печорского Урала и полуострова Канин. Сыктывкар. Изд-во: Коми книжное изд-во. 1964. С. 46-56.

10. Новицкий И.П. Петрология метаморфического комплекса полуострова Канин и Северного Тимана. Автореф. канд. дис. М. Изд-во: МГУ. 1976. 24 с.

11. Попов В.А., Попова В.И., Поляков В.О. Закономерные срастания минералов в пегматитах Ильменских гор // ЗРМО. 2006. Т. 135. Вып. 5. С. 48-59.

12. Попова В.И., Рассомахин М.А., Котляров В.А. Новые данные о минералогии гранитных пегматитов горы Сорочьей (Южный Урал) // Литосфера. 2016. № 4. С. 125-132.

13. Sun S., McDonough W. F. Chemical and isotopic systematics of oceanic basalts: implications for mantle composition and processes // Geological Society Special Publication. 1989. V. 42. P. 313-345.

14. Wan Fuad Wan Hassan Some characteristics of the heavy detrital minerals from Peninsular Malaysia // Geol. Soc. Malaysia. Bulletin 24. October 1989. P. 1-12. 